\title{
TITLE
}

Social inequalities in the association between temperature and mortality in a South

\section{European context.}

Marc Marí-Dell’Olmo ${ }^{1,2,3,4}$, Aurelio Tobías ${ }^{5}$, Anna Gómez¹, Maica Rodríguez-

Sanz $^{1,2,3,4}$, Patricia García de Olalla ${ }^{1}$, Esteve Camprubí ${ }^{1}$, Antonio Gasparrini ${ }^{6}$, Carme Borrell $^{1,2,3,4}$

${ }^{1}$ Agència de Salut Pública de Barcelona. Barcelona. Spain

${ }^{2}$ CIBER Epidemiología y Salud Pública (CIBERESP). Madrid. Spain.

${ }^{3}$ Institut d'Investigació Biomèdica (IIB Sant Pau). Barcelona. Spain.

${ }^{4}$ Universitat Pompeu Fabra. Barcelona. Spain.

${ }^{5}$ Consejo Superior de Investigaciones Científicas. Barcelona. Spain

${ }^{6}$ London School of Hygiene and Tropical Medicine. London. United Kingdom.

\section{Address for correspondence:}

Marc Marí-Dell’Olmo

Agència de Salut Pública de Barcelona

Plaça Lesseps 1

08023 Barcelona

Tel: 34-93-2384545

e-mail: mmari@aspb.cat 


\section{KEY WORDS}

Socioeconomic inequalities; mortality; temperature; cold; heat; climate change

\section{COMPETING INTERESTS}

The authors declare that they have no competing interests.

\section{COMPLIANCE WITH ETHICAL STANDARDS ETHICAL APPROVAL}

This article is based on a secondary analysis of administrative data, and does not contain any studies with human participants performed by any of the authors. Obtaining informed consent or approval by a medical ethics board was not required under national regulations. 


\section{ABSTRACT}

\section{Objectives}

To analyze social inequalities in the association between ambient temperature and mortality by sex, age and educational level, in the city of Barcelona for the period 19922015.

\section{Methods}

Mortality data are represented by daily counts for natural mortality. As a measure of socioeconomic position, we used the educational level of the deceased. We also considered age-group and sex. We considered, as a measure of exposure, the daily maximum temperatures. Time-series Poisson regression with distributed lag non-linear models were fitted for modelling the relationship between temperature and mortality.

\section{$\underline{\text { Results }}$}

Women had higher risk of mortality by hot temperatures than men. Temperaturemortality association (heat and cold) was evident for the elderly, except for heat-related mortality in women which was present in all age groups. Men with primary education or more were more vulnerable to moderate or extreme temperatures than those without studies. Finally, women were vulnerable to heat-related mortality in all educational levels while women without studies were more vulnerable to cold temperatures.

\section{Conclusions}

Social and economic individual characteristics play an important role in vulnerability to high and low temperatures. It is important that decision-making groups consider 
identified vulnerable subgroups when redacting and implementing climate change resilience and adaptation plans. 


\section{INTRODUCTION}

Several epidemiologic studies have well-documented the association between low or high temperatures and mortality in different parts of the world like Europe, North-America or East Asia (Curriero et al. 2002; O’Neill et al. 2003; Medina-Ramón and Schwartz 2007; Anderson and Bell 2009; de' Donato et al. 2015; Gasparrini et al. 2015; Onozuka and Hagihara 2015) This relationship has been described, generally, as a non-linear "U", "V" or "J"-shaped. The impact of temperatures on mortality represents a global public health issue (Baccini et al. 2008; McMichael et al. 2008; Costello et al. 2009; Analitis et al. 2014) that could be exacerbated by climate change events including more frequent, extreme and long-lasting episodes of particularly hot or cold temperatures (Zanobetti and Schwartz 2008; IPCC 2012). Despite the attention given to extreme weather events, most of the temperature-related mortality burden has been attributable to milder but nonoptimum temperatures (Gasparrini et al. 2015).

According to international agencies and institutions (IPCC, WHO and CDC) more research is needed to identify and characterize the groups that are more vulnerable to climate change health impacts, such as temperature-related-mortality (Woodward et al. 2014; World Health Organization (WHO) 2014; Manangan et al. 2015). The effects of temperatures on mortality are generally unequal across axes of inequality such as age, gender and socio-economic position (O’Neill et al. 2003; Mercer 2003; Medina-Ramón et al. 2006; Zanobetti et al. 2013b; Huang et al. 2015; Onozuka and Hagihara 2015; Li et al. 2017). Better knowledge of these modifiers is essential for planning suitable public health interventions and for the provision of reliable predictions of the effects of climate change (Villalbí and Ventayol 2016). Thus, for example, it has been reported that the elderly are the most susceptible to temperature-related mortality (Basu and Samet 2002; Mercer 2003; Basu 2009; Zanobetti et al. 2013a; Benmarhnia et al. 2015; Onozuka and 
Hagihara 2015), though inequalities among the different age groups is still under examination. Other studies, have identified women to be at higher risk-mortality, while others have showed no difference by gender or have observed men to be at higher risk (O’Neill et al. 2003; Medina-Ramón et al. 2006; Zanobetti et al. 2013b; Onozuka and Hagihara 2015). Regarding socioeconomic position, few studies have observed that it could modify temperature-related mortality while others have not (Curriero et al. 2002; O’Neill et al. 2003; Medina-Ramón et al. 2006; Ma et al. 2012; Son et al. 2013; Huang et al. 2015). However, to the best of our knowledge, no studies to date have investigated the effect modification on the association between (cold and hot) ambient temperatures and mortality by educational level in a European context. The mortality register of Barcelona is linked with the municipal census, providing the opportunity of obtaining the educational level of the deceased since 1992. Due to this linkage, it is possible to obtain long time series (24 years) that allow researchers to study in depth vulnerable groups according to their sex, age and educational level.

The objective of this study was to analyze social inequalities in the association between ambient temperature and mortality by sex, age and educational level, in the city of Barcelona for the period 1992-2015. 


\section{METHODS}

\section{Study design, unit of analysis, data and sources of information.}

This is a time-series study performed in the city of Barcelona, based on resident population. Daily data were collected from 1 January 1992 to 31 December 2015.

Mortality data were obtained from the mortality registry of Barcelona, which collects information from the mortality registry of the Department of Health of Catalonia and from the municipal population registry. The educational level is available through the record linkage between the registry and the municipal census. Mortality data are represented by daily deaths for all causes, excluding external causes, i.e. natural mortality (International Classification of Diseases, $9^{\text {th }}$ revision (ICD-9) codes $0-799$, and $10^{\text {th }}$ revision (ICD-10) codes A00-R99). Residents of Barcelona who died outside the city were also excluded.

As a measure of socioeconomic position, we used the educational level of the deceased (Galobardes et al. 2006). Educational level was categorized into 3 groups (without studies, primary education, more than primary education).

Deceased were also classified into 4 age groups (25-64 years, 65-74 years, 75-84 years, $\geq 85$ years). We selected the individuals aged 25 years or older because it is estimated that individuals of this age can have reached the highest educational level.

We considered, as a measure of exposure, the daily maximum temperatures (in ${ }^{\circ} \mathrm{C}$ ) for the study period in Barcelona. Temperature data were obtained from the "Servei Meteorològic de Catalunya" (METEOCAT). We have chosen the maximum temperature for the study since this measure is the one used to determine the warning thresholds in the Barcelona heatwave early warning system. 


\section{Data analysis}

All the analyses were performed for each sex separately. Time-series Poisson regression with distributed lag non-linear models (DLNM) were fitted for modelling the relationship between temperature and mortality, reported as relative risk (RR). DLNM provide a flexible way to capture the complex non-linear and lagged dependencies of exposureresponse relationships through the combination of two functions in a cross-basis function.(Gasparrini et al. 2010; Gasparrini 2014). Specifically, we modelled the exposure-response curve with a quadratic B-spline with three internal knots placed at the 10th, 75th, and 90th percentiles of location-specific temperature distributions, and the lag-response curve with a natural cubic B-spline with an intercept and three internal knots placed at equally spaced values in the log scale. We extended the lag period to 21 days to include the long delay of the effects of cold and to exclude deaths that were advanced by only a few days (harvesting effect). We then reduced the association to the overall temperature-mortality association, cumulating the risk during the lag period. Moreover, we have found the temperature at which risk of mortality is at a minimum, also called minimum mortality temperature (MMT), with its 95\% confidence interval (95\% CI) computed using an approximate parametric bootstrap with 50,000 simulated splines (Tobías et al. 2016). The majority of the MMTs obtained by each sex, age and educational level groups were close to $25^{\circ} \mathrm{C}$ and its $95 \% \mathrm{IC}$ always included this temperature value (see Table 1), so we decided to use $25^{\circ} \mathrm{C}$ as the reference temperature to compare the results between groups. We have summarized the mortality risks of moderate cold and hot temperatures by computing, respectively, the RRs at the $5^{\text {th }}$ and $95^{\text {th }}$ temperature percentiles using the $25^{\circ} \mathrm{C}$ as the reference. Moreover, the mortality risk of extreme cold temperatures was estimated by the RR at the $1^{\text {st }}$ percentile with respect the $5^{\text {th }}$ percentile. 
Similarly, the mortality risk of extreme heat was obtained by the RR at the $99^{\text {th }}$ percentile with respect the $95^{\text {th }}$ percentile. These temperature percentiles and the reference temperature of $25^{\circ} \mathrm{C}$ are displayed in the figures 1,2 and 3 . We investigated the effect modification by sex, age and educational level by estimating the relative effect modification (REM) index (Stafoggia et al. 2006).

Finally, for each day of the series (in each sex, age and educational level group) we used the overall cumulative RR corresponding to each day's temperature to calculate the attributable deaths and fraction of attributable deaths in the next 21 days, using a previously described method (Gasparrini and Leone 2014). The total attributable number (AN) of deaths caused by non-optimum temperatures is given by the sum of the contributions from all the days of the series, and the total attributable fraction (AF) is calculated through the ratio of AN with the total number of deaths. We also calculated the components attributable to extreme cold, moderate cold, moderate heat and extreme heat by summing the subsets corresponding the days with temperatures ranging between the cutoffs $5^{\text {th }}$ percentile, $25^{\circ} \mathrm{C}$ and $95^{\text {th }}$ percentile(Gasparrini et al. 2015). 


\section{RESULTS}

In Barcelona, the maximum daily temperatures during the period 1992-2015 ranged from $0.7^{\circ} \mathrm{C}$ to $38.4^{\circ} \mathrm{C}$, with a mean of $19.6^{\circ} \mathrm{C}$ (standard deviation $6.8^{\circ} \mathrm{C}$ ). Moreover, the $1^{\text {st }}, 5^{\text {th }}$, $50^{\text {th }}, 95^{\text {th }}$ and $99^{\text {th }}$ percentiles of maximum daily temperatures were $6.3,9.2,19.2,30.6$ and 33.2, respectively. Table 1 shows the number and percentage of deaths by sex, age groups and educational level in Barcelona during the period 1992-2015. The data set includes 164,853 men and 171,526 women. In the younger age group (25-64 years) there were fewer deaths among women (9.0\%) than among men (19.3\%), while in the older age group ( $\geq 85$ years) the percentage was higher in women $(48.8 \%)$ than in men $(24.6 \%)$. Most deceased women had no studies $(40.9 \%)$ or primary education (35.5\%) while, inversely, the majority of men had more than primary education (37.9\%).

Figure 1 shows the temperature-mortality association for men and women. In men, RRs curve has a "U" shape. However, in women, RRs curve has a "J" shape, showing a statistically significant effect in low and high temperatures, but the RRs are higher for the latter. We found differences between sexes that are summarized in Table 2. Specifically, the RRs point estimates of cold temperatures were similar in both sexes, while for hot temperatures the highest RRs were found in women. Thus, the RR at the $95^{\text {th }}$ percentile versus $25^{\circ} \mathrm{C}$ was 1.14 [95\%CI: $\left.(1.05 ; 1.24)\right]$ in women and 1.04 [95\%CI: $\left.(0.95 ; 1.13)\right]$ in men; while the RR at the $99^{\text {th }}$ versus the $95^{\text {th }}$ percentile was 1.35 [95\%CI: $\left.(1.26 ; 1.44)\right]$ in women and 1.15 [95\%CI: $(1.06 ; 1.23)]$ in men. The obtained REMs, studying the effect modification by sex, were $1.10(p$-value $=0.116)$ and $1.18(p$-value $=0.002)$, respectively (Supplementary table 1).

When considering age groups, by sex. In men, we found that cold has a significantly higher effect in the 65-74 and $\geq 85$ age groups and of heat in the $75-84$ and $\geq 85$ age groups 
(Figure 2). For example, in $\geq 85$ age group, the $\mathrm{RR}$ at the $5^{\text {th }}$ percentile versus $25^{\circ} \mathrm{C}$ was $1.30[95 \% \mathrm{CI}:(1.07 ; 1.58)]$ and the RR at the $99^{\text {th }}$ versus 95 th percentile was $1.18[95 \% \mathrm{CI}$ : $(1.02 ; 1.36)]$ (Table 2). In women, we found the most significant effect of cold in the 7584 age group and a significant effect of heat in all age groups (Figure 2). For example, the $\mathrm{RR}$ at the $5^{\text {th }}$ percentile versus $25^{\circ} \mathrm{C}$ was 1.40 [95\%CI: $\left.(1.17 ; 1.66)\right]$ in $75-84$ age group, and the RR at the $99^{\text {th }}$ versus 95 th percentile was 1.40 [95\%CI: $\left.(1.27 ; 1.54)\right]$ in the $\geq 85$ age group (Table 2 ). REMs show only statistically significant differences between age groups in women, the $\mathrm{RR}\left(95^{\text {th }}\right.$ percentile versus $\left.25^{\circ} \mathrm{C}\right)$ obtained in the $75-84$ age group being lower than the $\mathrm{RR}$ obtained in the $25-64$ age group $(\mathrm{REM}=0.72 ; p$-value $=$ 0.039) (Supplementary table 1).

We also studied the non-linear temperature-mortality association for each educational level group, by sex (Figure 3 and Table 2). In men, we found the most significant effects of temperature on mortality for cold temperatures in the groups with primary education and with more than primary education; and for extreme heat, the most significant values were found in the primary education group. For example, in the primary education group, the $\mathrm{RR}$ at the $5^{\text {th }}$ percentile versus $25^{\circ} \mathrm{C}$ was 1.31 [95\% CI: $\left.(1.12 ; 1.54)\right]$. In women, we found a significant effect of cold on mortality in the group without studies, which became non-significant when the education level increases. In contrast, we found a significant effect of heat in all the educational level groups. Thus, for women without studies, the $\mathrm{RR}$ at the $1^{\text {th }}$ versus $5^{\text {th }}$ percentile was 1.11 [95\%CI: $\left.(1.00 ; 1.24)\right]$, at the $5^{\text {th }}$ percentile versus $25^{\circ} \mathrm{C}$ was 1.28 [95\% CI: $\left.(1.10 ; 1.49)\right]$, at the $95^{\text {th }}$ percentile versus $25^{\circ} \mathrm{C}$ was 1.23 [95\%CI: $(1.08 ; 1.40)]$ and at the $99^{\text {th }}$ versus 95th was 1.31 [95\%CI: $\left.(1.18 ; 1.46)\right]$. REMs show that educational level could produce an effect modification on the association between moderate temperatures and mortality, specifically in cold temperatures for men and in hot temperatures for women (supplementary table 1). 
The total AF caused by temperature was $7.42 \%$ [95\%CI: $(2.68 ; 11.87)]$ in men and $8.05 \%$ [95\%CI: $(3.21 ; 12.48)]$ in women (Supplementary table 2). In men, the highest total AFs (statistically significant) were obtained among the age group of 85 and older and among those with more than primary education; while for women, the highest total AFs were obtained among the 75-84 age group and in the group without studies. Comparing temperatures, we obtain the highest AF for moderate cold temperatures in both sexes followed by extreme cold in men and extreme heat in women. Specifically, moderate cold temperatures produced 9130 [95\%CI: $(1793 ; 16061)]$ deaths in men and 8208 [95\%CI: $(586 ; 15230)]$ in women for the 23 year period (supplementary table 3 ). 


\section{DISCUSSION}

\section{Summary of the main results}

The results of our study suggest that women have a higher risk of mortality by hot temperatures than men. In general, the temperature-mortality association (heat and cold) was evident for the elderly; with the exception of heat-related mortality in women which was present in all age groups. Additionally, contrary to our expectations, men with primary studies or more were more vulnerable to moderate or extreme temperatures than those without studies. Finally, women were vulnerable to heat-related mortality in all educational levels while women without studies were more vulnerable to cold temperatures.

\section{Interpretation and significance of results}

\section{Gender inequalities}

Risks of mortality associated to cold temperatures were similar for both sexes, while risks of mortality associated to hot temperatures were higher in women. Our results are in line with the findings of previous studies that have analysed high and low temperature-related mortality (Zanobetti et al. 2013a; Onozuka and Hagihara 2015). Other studies, more focussed on the impacts of heat or heat waves on mortality, have also found that females were more vulnerable than men (Borrell et al. 2006; Stafoggia et al. 2006; Hajat et al. 2007; Basu 2009; Yu et al. 2010; Li et al. 2017). However other studies have not found differences between sexes (O’Neill et al. 2003; Medina-Ramón et al. 2006; Benmarhnia et al. 2015) These findings may be due to the social conditions of elderly females, who 
often live alone; and due to differences in thermoregulatory and physiological mechanisms (Onozuka and Hagihara 2015; Li et al. 2017)

\section{Age inequalities}

In men, we found a significant effect of cold on mortality for $\geq 65$ age group, while heat represents a significant risk of mortality for the $\geq 75$ age group. In women, we found that cold has its most significant effect on mortality in the 75-84 age group and a significant effect of heat on mortality in all age groups. This effect was higher in the $25-64$ and $\geq 85$ age groups. Several studies on the effects of temperature on mortality have also found a greater susceptibility of the elderly to both cold and hot temperatures. A reduced thermoregulatory capacity in the elderly, combined with a diminished ability to detect changes in their body temperature, may partially explain their increased susceptibility (Basu and Samet 2002; Mercer 2003; Basu 2009; Zanobetti et al. 2013a; Benmarhnia et al. 2015; Onozuka and Hagihara 2015; Li et al. 2017) Moreover, it is known that factors usually related with elderly as being confined to bed, having an illness, isolation or not leaving home each day, produce a greater risk of dying due to heat wave (Semenza et al. 1996). However, Onozuka et al. (2015) found that in Fukuoka (Japan) age was not an effect modifier for heat or cold extremes over last decades (Onozuka and Hagihara 2015).

\section{Educational inequalities}

In men, we found a significant effect of cold on mortality in those individuals with primary education or more. Regarding heat, we only found that extreme heat is related to mortality in the primary education group. In women, we found a significant effect of cold on mortality in the group without studies which became non-significant when the education level increased. On the other hand, we found a significant effect of heat in all the educational level groups. Studies performed in United States or Asia have found that 
the relation between mortality and hot or cold temperatures was modified by educational level. O'Neill et al. (2003) found that, in general, cold and hot effects were higher among the less educated (O’Neill et al. 2003). Ma W. et al. (2012) found no significant modifying effect of educational level, although residents with low education attainment had slightly higher temperature mortality effects.(Ma et al. 2012) Huang Z. et al. (2015) found that people with lower educational level had a significant risk of heat-related mortality. However, the cold temperature - mortality associations were similar between the studied educational level groups (Huang et al. 2015). Medina-Ramón et al. (2006) showed that subjects with lower educational level were more susceptible to extreme heat and no differences were found for extreme cold. (Medina-Ramón et al. 2006). Similarly, multilevel and ecological studies (using geographical areas as unit of analysis) have found analogous results (Curriero et al. 2002; Hajat et al. 2007; Huang et al. 2015). To our knowledge, only one study performed in Seoul (Korea) has investigated the effect modification on the association between (cold and hot) temperatures and mortality by educational level stratifying by sex.(Son et al. 2013) The authors found that for both men and women, the educational group with the highest cold and heat effects was the lowest educational level. However, the highest effect in cold-related cardiovascular mortality was observed for the most educated group. In Barcelona, Borrell C. et al. (2006) found that the excess mortality during the summer of 2003 was observed in all educational groups among women, but in some age groups the increase was larger for women with low education or with less than primary education (Borrell et al. 2006). Persons with less educational attainment, which may be a predictor of low socioeconomic status, were more likely to have poorer health status, limited access to health care and poorer living conditions (Marmot Review Team 2011). Moreover, the access to proper housing, necessary for bearing extreme temperatures, can be influenced by education (Marí- 
Dell'Olmo et al. 2016; Almendra et al. 2017; Peralta et al. 2017). However, the significant effect of cold on mortality in men with primary education or more could be due to the fact that in Spain, in the earliest stages of the tobacco epidemic, men with higher socioeconomic position had a higher smoking prevalence (Lopez et al. 1994). These men could be now more vulnerable to the effect of cold.

\section{Methodological considerations}

To our advantage, we had access to the educational level of the deceased as a proxy of socioeconomic position. It should be noted that the majority of mortality registers do not have variables of socioeconomic position of the deceased of any kind. In our study, educational level was obtained through a continuous record linkage between the mortality register and the Municipal Census (97.3\% of cases were linked). Another strength of our study is that it is one of the first to explore in detail the effect modification of temperaturerelated mortality by sex, age and educational level using large daily time series of 24 years in a European context. Moreover, we have used the most recent and sophisticated statistical methodology under the DLNM framework to take into account the complex and heterogeneous temperature-mortality dependency. However, as a limitation, we must mention that these statistical methods have not allowed us to analyze educational level differences adjusting the analyses by age. This issue could not be addressed through stratifying by sex, educational level and age because categories ended up with small numbers of deaths, leading to a lack of statistical power. 


\section{Conclusions}

Our study has shown that social and economic individual characteristics play an important role in vulnerability to high and low temperatures. It is important that climate change resilience and adaptation plans consider these vulnerable subgroups. It is necessary to consider monitoring cold spells, using specific early warning systems as the ones already functioning for heat waves. This is important since, in our study, cold temperatures have demonstrated mortality risks similar or even higher to hot temperatures and also because specific vulnerable groups have been detected. 


\section{REFERENCES}

Almendra R, Santana P, Vasconcelos J (2017) Evidence of social deprivation on the spatial patterns of excess winter mortality. Int J Public Health 62:849-856. doi: $10.1007 / \mathrm{s} 00038-017-0964-7$

Analitis A, Michelozzi P, D'Ippoliti D, et al (2014) Effects of heat waves on mortality: effect modification and confounding by air pollutants. Epidemiology 25:. doi: 10.1097/EDE.0b013e31828ac01b

Anderson BG, Bell ML (2009) Weather-Related Mortality: How Heat, Cold, and Heat Waves Affect Mortality in the United States. Epidemiology 20:205-213. doi: 10.1097/EDE.0b013e318190ee08

Baccini M, Biggeri A, Accetta G, et al (2008) Heat effects on mortality in 15 European cities. Epidemiology 19:711-719. doi: 10.1097/EDE.0b013e318176bfcd

Basu R (2009) High ambient temperature and mortality: a review of epidemiologic studies from 2001 to 2008. Environ Health 8:40. doi: 10.1186/1476-069X-8-40; 10.1186/1476-069X-8-40

Basu R, Samet JM (2002) Relation between elevated ambient temperature and mortality: A review of the epidemiologic evidence. Epidemiol Rev 24:190-202. doi: 10.1093/epirev/mxf007

Benmarhnia T, Deguen S, Kaufman JS, Smargiassi A (2015) Vulnerability to Heatrelated Mortality: A Systematic Review, Meta-analysis, and Meta-regression Analysis. Epidemiology 26:781-793. doi: 10.1097/EDE.0000000000000375

Borrell C, Mari-Dell'Olmo M, Rodriguez-Sanz M, et al (2006) Socioeconomic position and excess mortality during the heat wave of 2003 in Barcelona. Eur J Epidemiol 21:633-640. doi: 10.1007/s10654-006-9047-4

Costello A, Abbas M, Allen A, et al (2009) Managing the health effects of climate change. Lancet and University College London Institute for Global Health Commission. Lancet 373:1693-1733. doi: 10.1016/S0140-6736(09)60935-1

Curriero FC, Heiner KS, Samet JM, et al (2002) Temperature and mortality in 11 cities 
of the eastern United States. Am J Epidemiol 155:80-87. doi: 10.1093/aje/155.1.80

de' Donato FK, Leone M, Scortichini M, et al (2015) Changes in the effect of heat on mortality in the last 20 years in nine European cities. Results from the PHASE project. Int J Environ Res Public Health 12:15567-15583. doi: 10.3390/ijerph121215006

Galobardes B, Shaw M, Lawlor DA, et al (2006) Indicators of socioeconomic position (part 1). J Epidemiol Community Health 60:7-12. doi: 10.1136/jech.2004.023531

Gasparrini A (2014) Modeling exposure-lag-response associations with distributed lag non-linear models. Stat Med 33:881-899. doi: 10.1002/sim.5963

Gasparrini A, Armstrong B, Kenward MG (2010) Distributed lag non-linear models. Stat Med 29:2224-2234. doi: 10.1002/sim.3940

Gasparrini A, Guo Y-LLLLY, Hashizume M, et al (2015) Mortality risk attributable to high and low ambient temperature: A multicountry observational study. Lancet 386:369-375. doi: 10.1016/S0140-6736(14)62114-0

Gasparrini A, Leone M (2014) Attributable risk from distributed lag models. BMC Med Res Methodol 14:55. doi: 10.1186/1471-2288-14-55

Hajat S, Kovats RS, Lachowycz K (2007) Heat-related and cold-related deaths in England and Wales: who is at risk? Occup Environ Med 64:93-100. doi: 10.1136/oem.2006.029017

Huang Z, Lin H, Liu Y, et al (2015) Individual-level and community-level effect modifiers of the temperature-mortality relationship in 66 Chinese communities. BMJ Open 5:e009172. doi: 10.1136/bmjopen-2015-009172

IPCC (2012) Managing the risks of extreme events and disasters to advance climate change adaptation. Special Report of the Intergovernmental Panel on Climate Change

Li J, Xu X, Yang J, et al (2017) Ambient high temperature and mortality in Jinan, China: A study of heat thresholds and vulnerable populations. Environ Res 156:657-664. doi: 10.1016/j.envres.2017.04.020 
Lopez a. D, Collishaw NE, Piha T (1994) A descriptive model of the cigarette epidemic in developed countries. Tob Control 3:242-247. doi: 10.1136/tc.3.3.242

Ma W, Yang C, Tan J, et al (2012) Modifiers of the temperature-mortality association in Shanghai, China. Int J Biometeorol 56:205-207. doi: 10.1007/s00484-011-0406-9

Manangan AP, Uejio CK, Saha S, et al (2015) Assessing Health Vulnerability to Climate Change. Cent Dis Control Prev 1-23

Marí-Dell'Olmo M, Novoa AM, Camprubí L, et al (2016) Housing Policies and Health Inequalities. Int J Heal Serv 0:1-26. doi: 10.1177/0020731416684292

Marmot Review Team (2011) The Health Impacts of Cold Homes and Fuel Poverty. In: Friends Earth Marmot Rev. Team

McMichael AJ, Wilkinson P, Kovats RS, et al (2008) International study of temperature, heat and urban mortality: The "ISOTHURM" project. Int J Epidemiol 37:1121-1131. doi: 10.1093/ije/dyn086

Medina-Ramón M, Schwartz J (2007) Temperature, temperature extremes, and mortality: a study of acclimatisation and effect modification in 50 US cities. Occup Env Med 64:827-833. doi: 10.1136/oem.2007.033175

Medina-Ramón M, Zanobetti A, Cavanagh DP, Schwartz J (2006) Extreme temperatures and mortality: Assessing effect modification by personal characteristics and specific cause of death in a multi-city case-only analysis. Environ Health Perspect 114:1331-1336. doi: 10.1289/ehp.9074

Mercer JB (2003) Cold--an underrated risk factor for health. Environ Res 92:8-13

O’Neill MS, Zanobetti A, Schwartz J (2003) Modifiers of the temperature and mortality association in seven US cities. Am J Epidemiol 157:1074-1082. doi: 10.1093/aje/kwg096

Onozuka D, Hagihara A (2015) Variation in vulnerability to extreme-temperaturerelated mortality in Japan: A 40-year time-series analysis. Environ Res 140:177184. doi: 10.1016/j.envres.2015.03.031 
Peralta A, Camprubí L, Rodríguez-Sanz M, et al (2017) Impact of energy efficiency interventions in public housing buildings on cold-related mortality: a casecrossover analysis. Int J Epidemiol dyw335. doi: 10.1093/ije/dyw335

Semenza JC, Rubin CH, Falter KH, et al (1996) Heat-related deaths during the July 1995 heat wave in Chicago. N Engl J Med 335:84-90. doi: 10.1056/NEJM199607113350203

Son J, Lee J, Anderson GB, et al (2013) Vulnerability to temperature-related mortality in Seoul , Korea. 6:. doi: 10.1088/1748-9326/6/3/034027.Vulnerability

Stafoggia M, Forastiere F, Agostini D, et al (2006) Vulnerability to Heat-Related Mortality: A Multicity, Population-Based, Case-Crossover Analysis. Epidemiology 17:315-323. doi: 10.1097/01.ede.0000208477.36665.34

Tobías A, Armstrong B, Gasparrini A (2016) Investigating Uncertainty in the Minimum Mortality Temperature. Epidemiology 1. doi: 10.1097/EDE.0000000000000567

Villalbí JR, Ventayol I (2016) Climate change and health in the urban context: the experience of Barcelona. Int J Heal Serv 46:389-405. doi: $10.1177 / 0020731416643444$

Woodward A, Smith KR, Campbell-Lendrum D, et al (2014) Climate change and health: On the latest IPCC report. Lancet 383:1185-1189. doi: 10.1016/S01406736(14)60576-6

World Health Organization (WHO) (2014) WHO guidance to protect health from climate change through health adaptation planning. 27

Yu W, Vaneckova P, Mengersen K, et al (2010) Is the association between temperature and mortality modified by age, gender and socio-economic status? Sci Total Environ 408:3513-3518. doi: 10.1016/j.scitotenv.2010.04.058

Zanobetti A, O’Neill MS, Gronlund CJ, Schwartz JD (2013a) Susceptibility to Mortality in Weather Extremes. Epidemiology 24:809-819. doi: 10.1097/01.ede.0000434432.06765.91

Zanobetti A, O’Neill MS, Gronlund CJ, Schwartz JD (2013b) Susceptibility to mortality 
in weather extremes: effect modification by personal and small-area characteristics.

Epidemiology 24:809-19. doi: 10.1097/01.ede.0000434432.06765.91

Zanobetti A, Schwartz J (2008) Temperature and Mortality in Nine US Cities.

Epidemiology 19:563-570. doi: 10.1097/EDE.0b013e31816d652d 
Table 1. Number and percentage of deaths. and minimum mortality temperature (MMT) and its $95 \%$ confidence interval (95\%CI).

by sex, age and educational level groups. Barcelona (Spain), period 1992-2015.

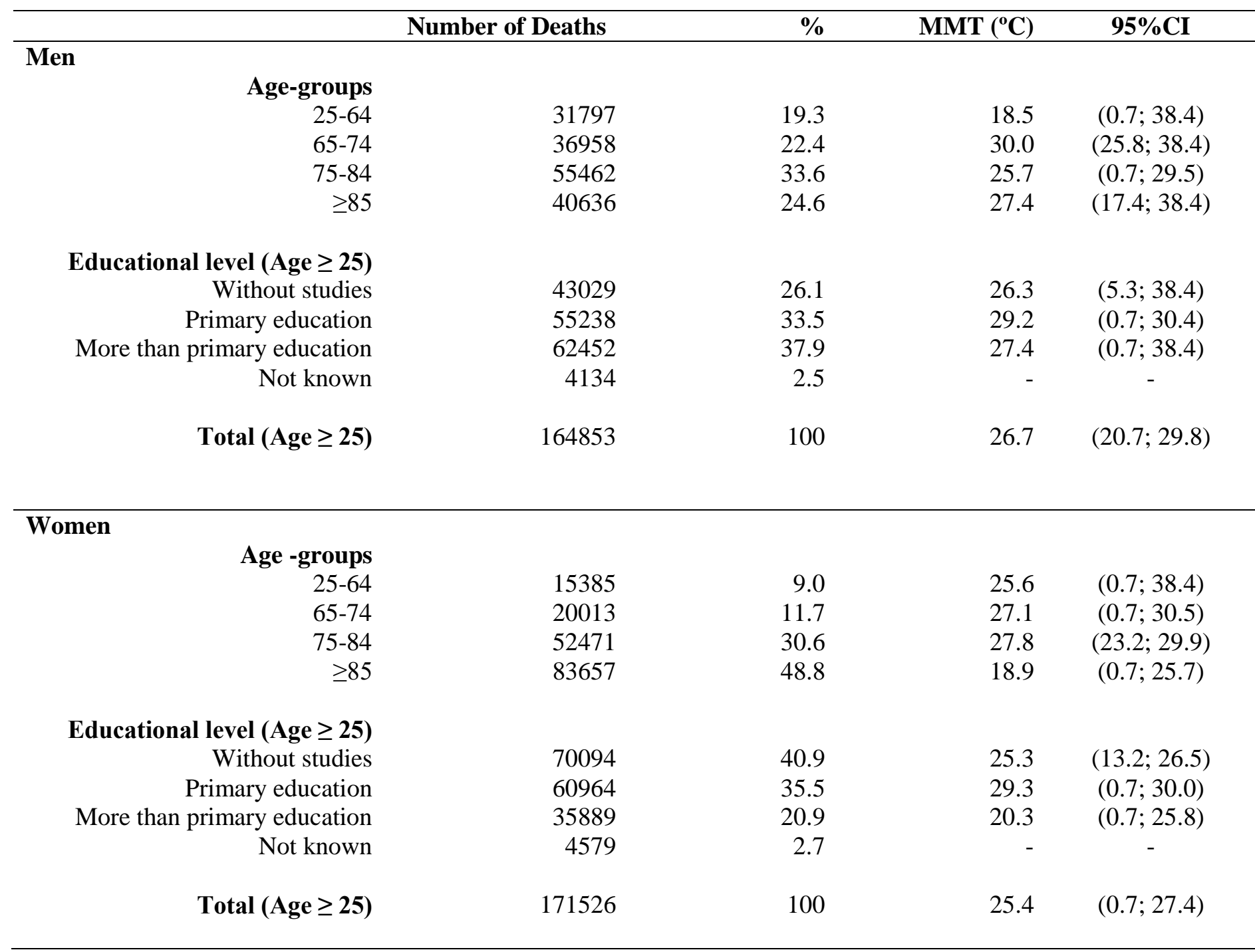


Table 2. Relative risks (RR) for mortality and its $95 \%$ confidence interval (95\%CI) by sex, age and educational level groups. Barcelona (Spain), period $1992-2015$.

\begin{tabular}{|c|c|c|c|c|c|c|c|c|}
\hline & \multicolumn{2}{|c|}{$\begin{array}{c}6.3^{\circ} \mathrm{C}(1 \mathrm{st} \mathrm{P}) \\
\text { vs } 9.2^{\circ} \mathrm{C}(5 \text { th } \mathrm{P})\end{array}$} & \multicolumn{2}{|c|}{$\begin{array}{l}9.2^{\circ} \mathrm{C}(5 \text { th } \mathrm{P}) \\
\text { vs } 25^{\circ} \mathrm{C}\end{array}$} & \multicolumn{2}{|c|}{$\begin{array}{l}30.6^{\circ} \mathrm{C}(95 \text { th } \mathrm{P}) \\
\text { vs } 25^{\circ} \mathrm{C}\end{array}$} & \multicolumn{2}{|c|}{$\begin{array}{c}33.2^{\circ} \mathrm{C}(99 \text { th } \mathrm{P}) \\
\text { vs } 30.6^{\circ} \mathrm{C}(95 \text { th } \mathrm{P})\end{array}$} \\
\hline & $\mathbf{R R}$ & $95 \% \mathrm{CI}$ & RR & $95 \% \mathrm{CI}$ & RR & 95\% CI & $\mathbf{R R}$ & $95 \% \mathrm{CI}$ \\
\hline \multicolumn{9}{|l|}{ Men } \\
\hline Age-groups & & & & & & & & \\
\hline $25-64$ & 0.98 & $(0.83 ; 1.18)$ & 1.06 & $(0.85 ; 1.33)$ & 1.00 & $(0.83 ; 1.21)$ & 1.09 & $(0.92 ; 1.30)$ \\
\hline $65-74$ & 1.19 & $(1.02 ; 1.40)$ & 1.31 & $(1.07 ; 1.61)$ & 0.92 & $(0.77 ; 1.10)$ & 1.07 & $(0.91 ; 1.25)$ \\
\hline $75-84$ & 1.06 & $(0.94 ; 1.20)$ & 1.18 & $(0.99 ; 1.39)$ & 1.16 & $(1.00 ; 1.34)$ & 1.19 & $(1.05 ; 1.35)$ \\
\hline$\geq 85$ & 1.13 & $(0.98 ; 1.30)$ & 1.30 & $(1.07 ; 1.58)$ & 1.03 & $(0.87 ; 1.22)$ & 1.18 & $(1.02 ; 1.36)$ \\
\hline \multicolumn{9}{|l|}{ Educational level (Age $\geq 25)$} \\
\hline Without studies & 1.15 & $(0.99 ; 1.32)$ & 1.04 & $(0.86 ; 1.26)$ & 1.04 & $(0.88 ; 1.23)$ & 1.11 & $(0.96 ; 1.29)$ \\
\hline Primary education & 1.08 & $(0.95 ; 1.22)$ & 1.23 & $(1.04 ; 1.46)$ & 1.02 & $(0.88 ; 1.17)$ & 1.20 & $(1.06 ; 1.36)$ \\
\hline More than primary education & 1.09 & $(0.97 ; 1.23)$ & 1.31 & $(1.12 ; 1.54)$ & 1.02 & $(0.89 ; 1.16)$ & 1.09 & $(0.97 ; 1.23)$ \\
\hline Total $($ Age $\geq 25)$ & 1.09 & $(1.02 ; 1.18)$ & 1.21 & $(1.10 ; 1.33)$ & 1.04 & $(0.95 ; 1.13)$ & 1.15 & $(1.06 ; 1.23)$ \\
\hline
\end{tabular}

\begin{tabular}{|c|c|c|c|c|c|c|c|c|}
\hline \multicolumn{9}{|l|}{ Women } \\
\hline Age -groups & & & & & & & & \\
\hline $25-64$ & 1.02 & $(0.79 ; 1.31)$ & 1.22 & $(0.89 ; 1.69)$ & 1.43 & $(1.09 ; 1.87)$ & 1.20 & $(0.94 ; 1.52)$ \\
\hline $65-74$ & 1.07 & $(0.86 ; 1.33)$ & 1.25 & $(0.95 ; 1.66)$ & 1.06 & $(0.83 ; 1.35)$ & 1.29 & $(1.04 ; 1.59)$ \\
\hline $75-84$ & 1.15 & $(1.01 ; 1.30)$ & 1.40 & $(1.17 ; 1.66)$ & 1.03 & $(0.89 ; 1.19)$ & 1.30 & $(1.15 ; 1.47)$ \\
\hline$\geq 85$ & 1.03 & $(0.93 ; 1.13)$ & 1.07 & $(0.93 ; 1.22)$ & 1.18 & $(1.05 ; 1.32)$ & 1.40 & $(1.27 ; 1.54)$ \\
\hline \multicolumn{9}{|l|}{ Educational level (Age $\geq 25$ ) } \\
\hline Without studies & 1.11 & $(1.00 ; 1.24)$ & 1.28 & $(1.10 ; 1.49)$ & 1.23 & $(1.08 ; 1.40)$ & 1.31 & $(1.18 ; 1.46)$ \\
\hline Primary education & 1.04 & $(0.93 ; 1.17)$ & 1.15 & $(0.98 ; 1.36)$ & 0.97 & $(0.84 ; 1.10)$ & 1.40 & $(1.25 ; 1.56)$ \\
\hline More than primary education & 0.98 & $(0.83 ; 1.14)$ & 1.14 & $(0.93 ; 1.41)$ & 1.29 & $(1.09 ; 1.53)$ & 1.31 & $(1.13 ; 1.51)$ \\
\hline Total (Age $\geq 25)$ & 1.07 & $(0.99 ; 1.15)$ & 1.20 & $(1.08 ; 1.32)$ & 1.14 & $(1.05 ; 1.24)$ & 1.35 & $(1.26 ; 1.44)$ \\
\hline
\end{tabular}

P: temperature location-specific percentile 


\section{FIGURE CAPTIONS}

Figure 1. Overall cumulative temperature-mortality association (Relative risk -black solid line- with its 95\% Confidence Interval -shaded grey-) by sex. Barcelona (Spain), period 1992-2005.

Figure 2. Overall cumulative temperature-mortality (Relative risk -black solid linewith its 95\% Confidence Interval -shaded grey-) by sex and age-groups. Barcelona (Spain), period 1992-2005.

Figure 3. Overall cumulative temperature-mortality association (Relative risk -black solid line- with its 95\% Confidence Interval -shaded grey-) by sex and educational level. Barcelona (Spain), period 1992-2005. 
(a) Men

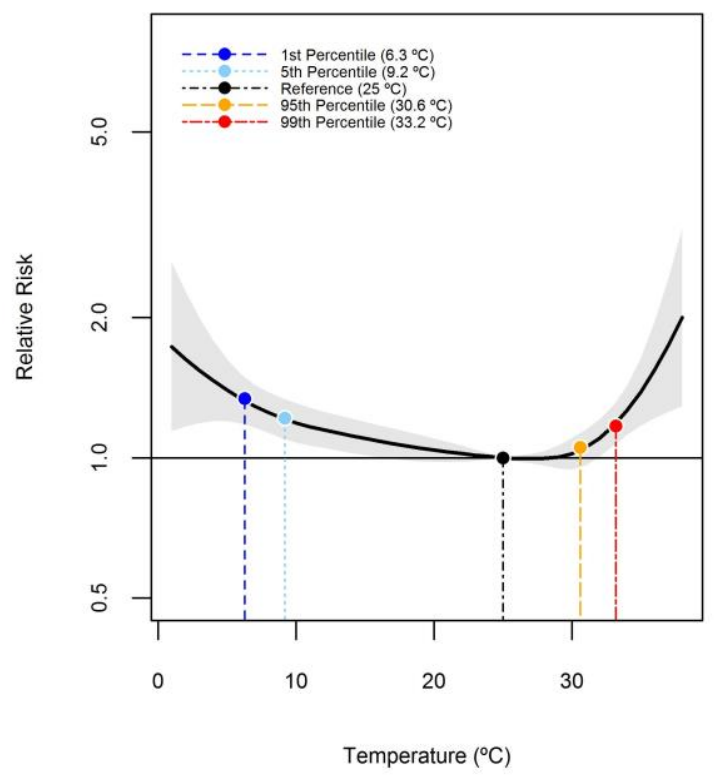

(b) Women

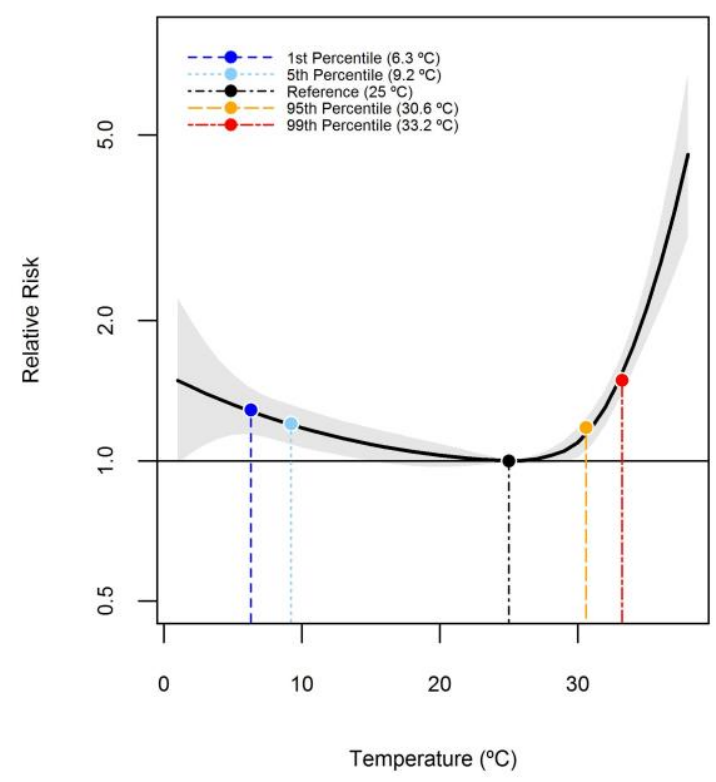



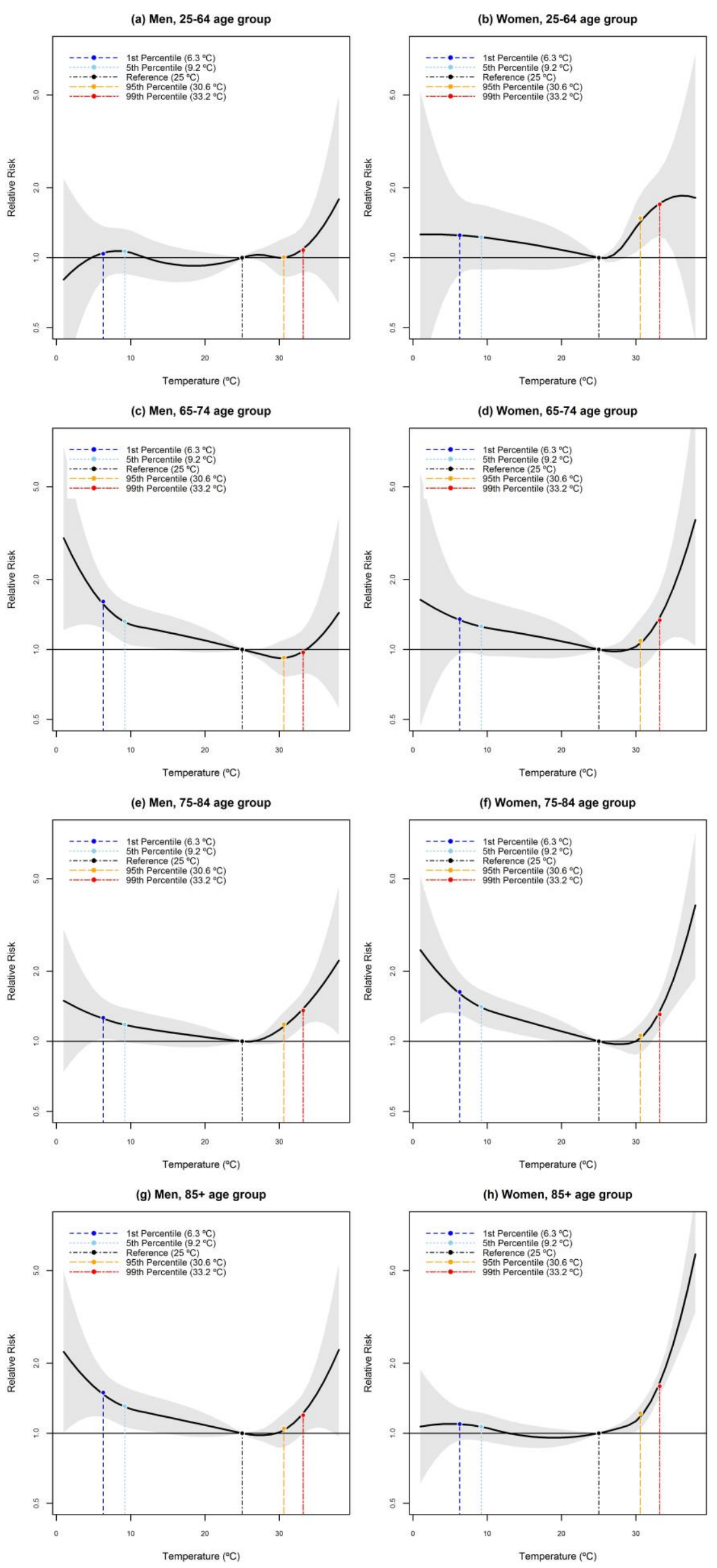
(a) Men, without studies

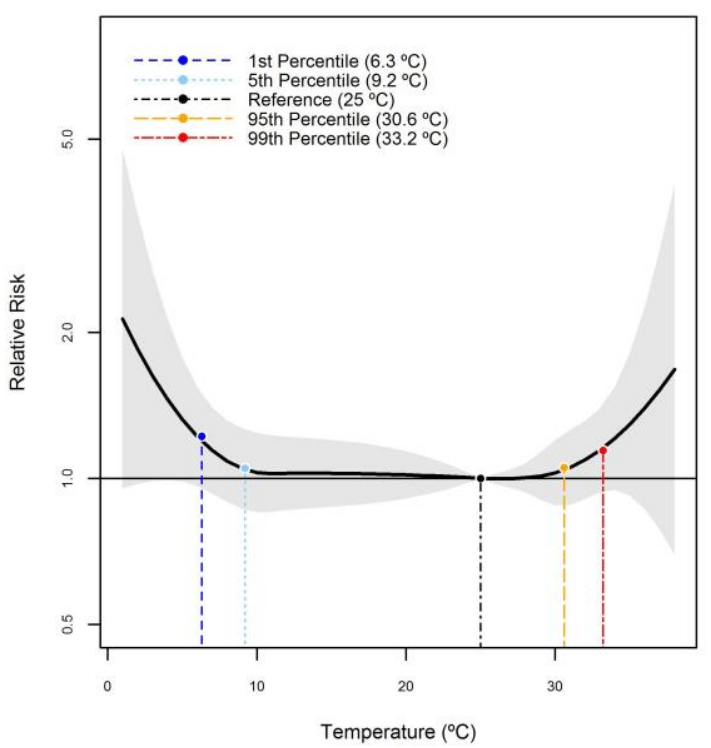

(c) Men, primary education

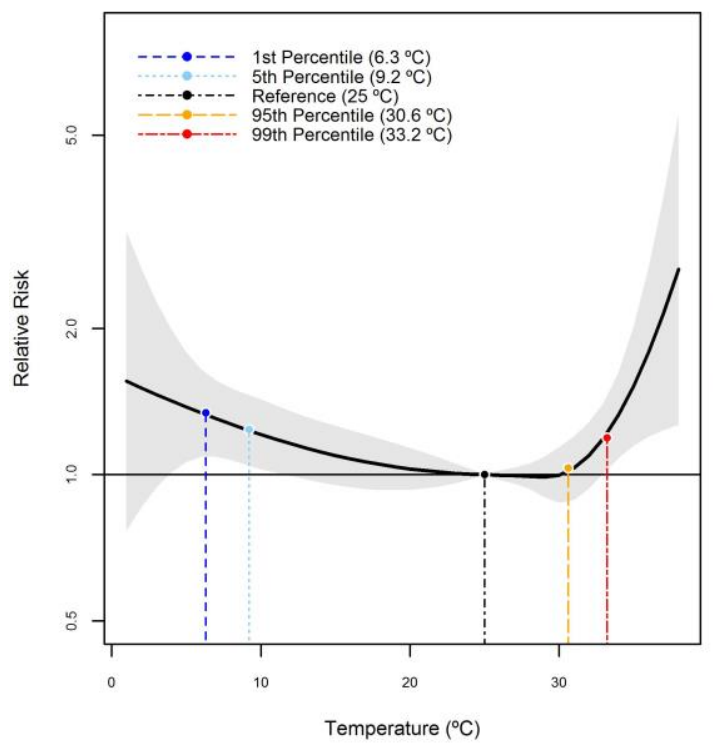

(e) Men, more than primary education

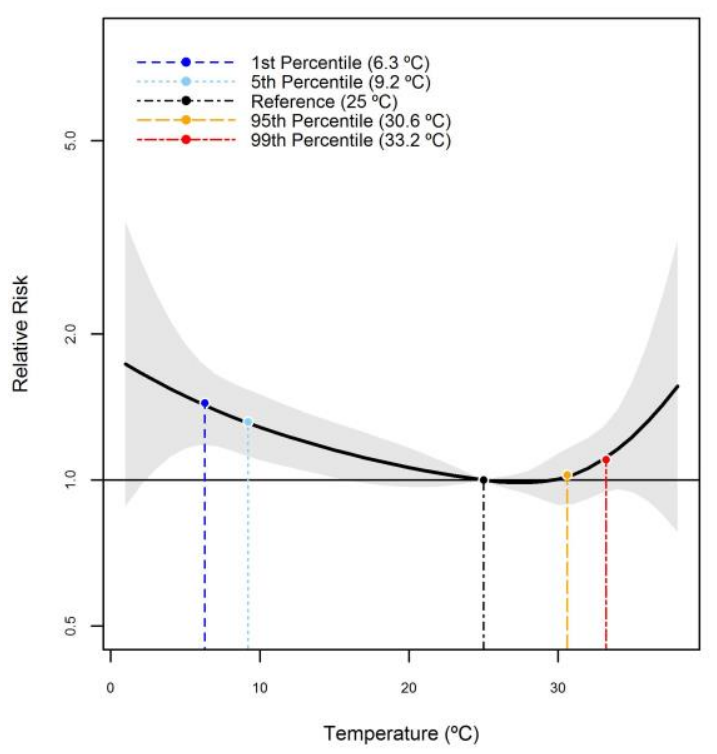

(b) Women, without studies

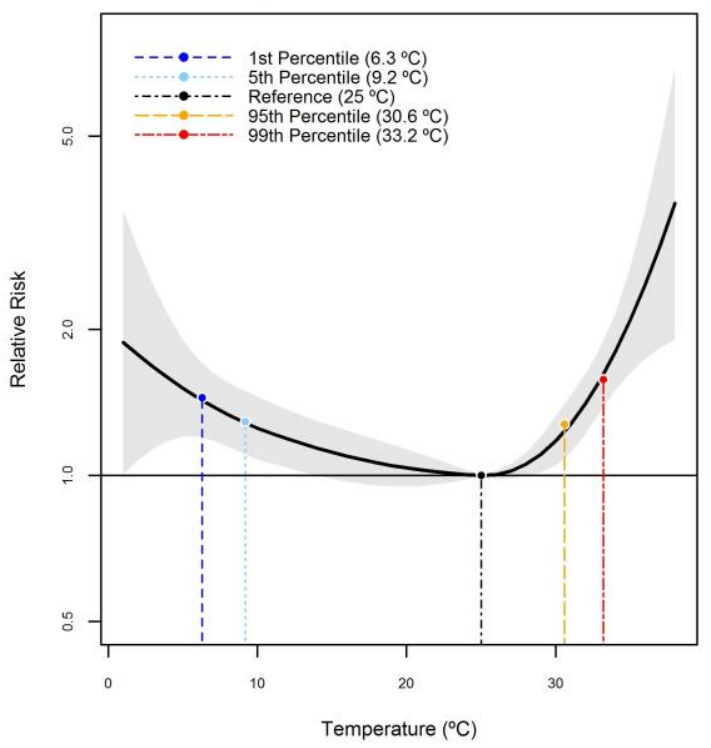

(d) Women, primary education

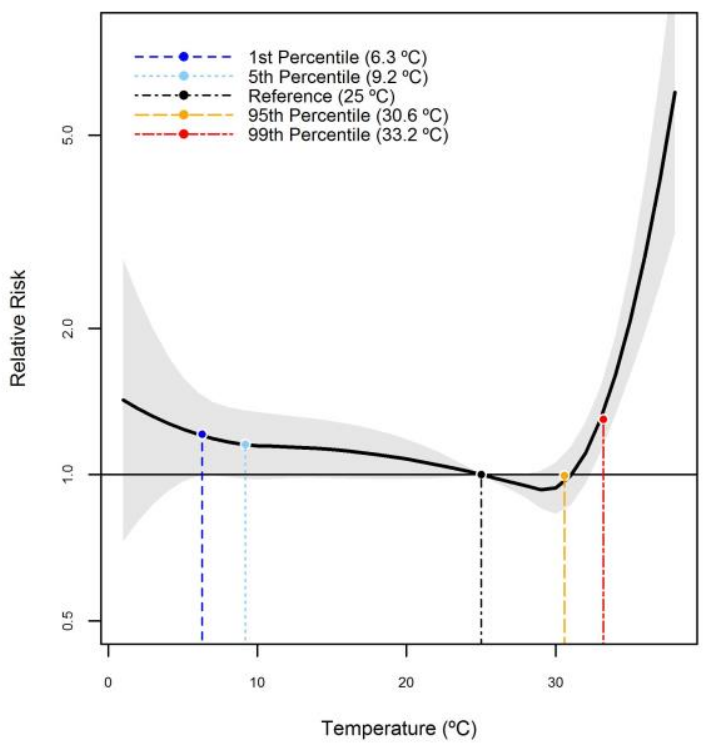

(f) Women, more than primary education

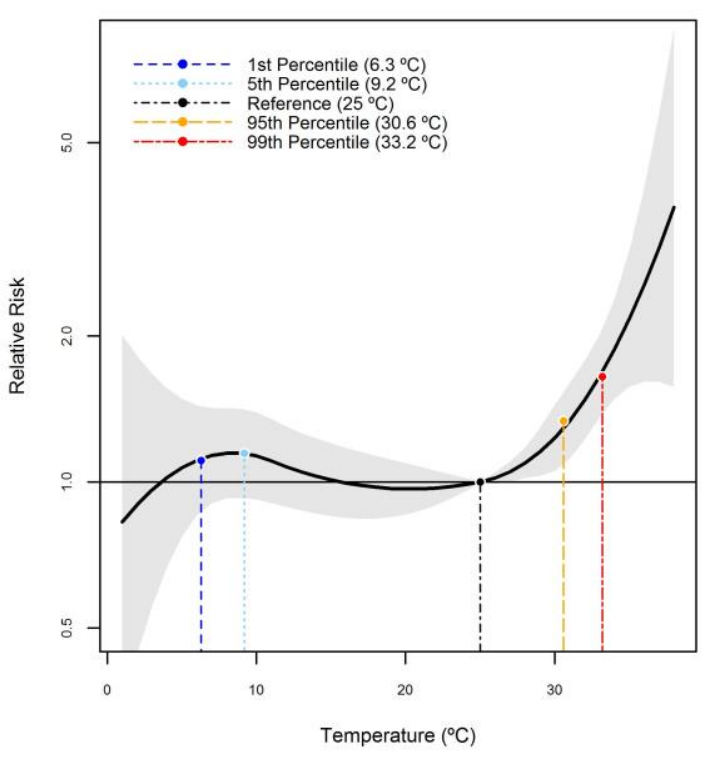




\section{SUPPLEMENTARY MATERIAL}

Title: Social inequalities in the association between temperature and mortality in a South European context

Journal: International Journal of Public Health

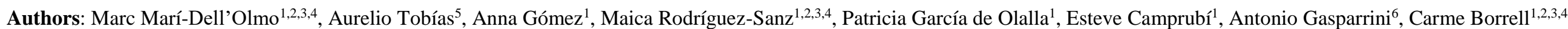

\section{Affiliations:}

${ }^{1}$ Agència de Salut Pública de Barcelona. Barcelona. Spain

${ }^{2}$ CIBER Epidemiología y Salud Pública (CIBERESP). Madrid. Spain.

${ }^{3}$ Institut d'Investigació Biomèdica (IIB Sant Pau). Barcelona. Spain.

${ }^{4}$ Universitat Pompeu Fabra. Barcelona. Spain.

${ }^{5}$ Consejo Superior de Investigaciones Científicas. Barcelona. Spain

${ }^{6}$ London School of Hygiene and Tropical Medicine. London. United Kingdom. 


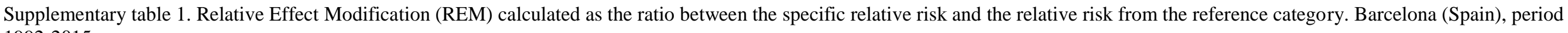
1992-2015.

\begin{tabular}{|c|c|c|c|c|c|c|c|c|}
\hline & \multicolumn{2}{|c|}{$\begin{array}{c}6.3^{\circ} \mathrm{C}(1 \text { st P }) \\
\text { vs } 9.2^{\circ} \mathrm{C}(5 \text { th P })\end{array}$} & \multicolumn{2}{|c|}{$\begin{array}{c}9.2^{\circ} \mathrm{C}(5 \text { th } \mathrm{P}) \\
\text { vs } 25^{\circ} \mathrm{C} \\
\end{array}$} & \multicolumn{2}{|c|}{$\begin{array}{c}30.6^{\circ} \mathrm{C}(95 \text { th } \mathrm{P}) \\
\text { vs } 25^{\circ} \mathrm{C}\end{array}$} & \multicolumn{2}{|c|}{$\begin{array}{c}33.2^{\circ} \mathrm{C}(99 \text { th } \mathrm{P}) \\
\text { vs } 30.6^{\circ} \mathrm{C}(95 \text { th } \mathrm{P})\end{array}$} \\
\hline & REM & p-value & REM & p-value & REM & p-value & REM & p-value \\
\hline \multicolumn{9}{|l|}{ Men } \\
\hline \multicolumn{9}{|l|}{ Age-groups } \\
\hline $25-64$ & 1 & - & 1 & - & 1 & - & 1 & - \\
\hline $65-74$ & 1.21 & 0.115 & 1.23 & 0.173 & 0.92 & 0.530 & 0.98 & 0.859 \\
\hline $75-84$ & 1.08 & 0.486 & 1.11 & 0.478 & 1.16 & 0.232 & 1.09 & 0.411 \\
\hline$\geq 85$ & 1.15 & 0.224 & 1.22 & 0.189 & 1.03 & 0.819 & 1.08 & 0.490 \\
\hline \multicolumn{9}{|l|}{ Educational level $($ Age $\geq 25)$} \\
\hline Without studies & 1.05 & 0.587 & 0.8 & 0.071 & 1.02 & 0.824 & 1.01 & 0.888 \\
\hline Primary education & 0.99 & 0.913 & 0.94 & 0.606 & 1.00 & 0.996 & 1.09 & 0.299 \\
\hline More than primary education & 1 & - & 1 & - & 1 & - & 1 & - \\
\hline \multicolumn{9}{|l|}{ Women } \\
\hline \multicolumn{9}{|l|}{ Age -groups } \\
\hline $25-64$ & 1 & - & 1 & - & 1 & - & 1 & - \\
\hline $65-74$ & 1.05 & 0.779 & 1.02 & 0.916 & 0.74 & 0.112 & 1.08 & 0.652 \\
\hline $75-84$ & 1.13 & 0.410 & 1.14 & 0.478 & 0.72 & 0.039 & 1.08 & 0.553 \\
\hline$\geq 85$ & 1.01 & 0.951 & 0.87 & 0.434 & 0.82 & 0.197 & 1.17 & 0.238 \\
\hline \multicolumn{9}{|l|}{ Educational level (Age $\geq 25)$} \\
\hline Without studies & 1.14 & 0.181 & 1.12 & 0.388 & 0.95 & 0.670 & 1 & 0.980 \\
\hline Primary education & 1.07 & 0.508 & 1.01 & 0.951 & 0.75 & 0.009 & 1.07 & 0.484 \\
\hline More than primary education & 1 & - & 1 & - & 1 & - & 1 & - \\
\hline \multicolumn{9}{|l|}{ Total } \\
\hline \multicolumn{9}{|l|}{ Sex-groups (Age $\geq 25)$} \\
\hline Men & 1 & - & 1 & - & 1 & - & 1 & - \\
\hline Women & 0.98 & 0.636 & 0.99 & 0.869 & 1.1 & 0.116 & 1.18 & 0.002 \\
\hline
\end{tabular}


Supplementary table 2. Fraction of attributable (AF) deaths caused by non-optimum temperatures and its $95 \%$ confidence interval (95\%CI) by sex, age and educational level groups. Barcelona (Spain), period 1992-2015.

$\begin{array}{ccccc}\text { All temperatures } & \text { Extreme cold } & \text { Moderate cold } & \text { Moderate heat } & \text { Extreme heat } \\ & {\left[\text { lower than } 9.2^{\circ} \mathrm{C}(5 \text { th }\right.} & {\left[9.2^{\circ} \mathrm{C}(5 \text { th } \mathrm{P})-25^{\circ} \mathrm{C}\right]} & {\left[25^{\circ} \mathrm{C}-30.6^{\circ} \mathrm{C}(95 \text { th } \mathrm{P})\right]} & {\left[\text { higher than } 30.6^{\circ} \mathrm{C}\right.}\end{array}$

P)]

(95th P)]

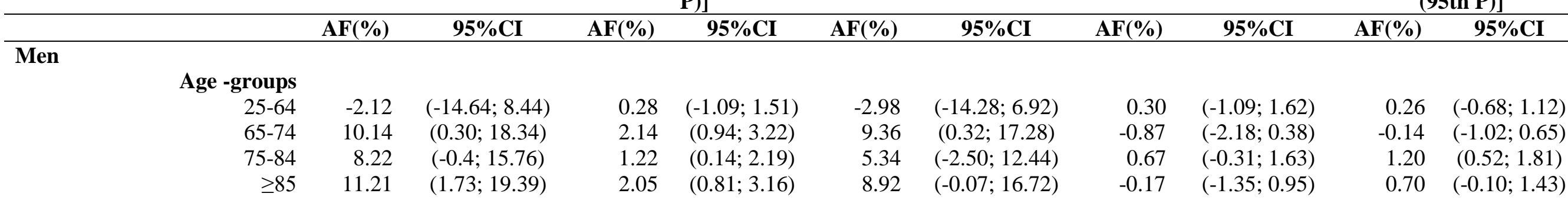

Educational level (Age $\geq 25)$

Without studies

Primary education

More than primary education

$\begin{array}{llllllllll}2.81 & (-7.87 ; 11.88) & 0.79 & (-0.48 ; 1.95) & 1.35 & (-8.41 ; 9.90) & 0.11 & (-1.02 ; 1.21) & 0.51 & (-0.25 ; 1.21) \\ 7.27 & (-1.24 ; 14.75) & 1.50 & (0.46 ; 2.48) & 5.42 & (-2.49 ; 12.47) & -0.08 & (-1.11 ; 0.90) & 0.64 & (-0.05 ; 1.27) \\ 9.68 & (2.31 ; 16.26) & 1.78 & (0.88 ; 2.61) & 7.93 & (0.95 ; 14.19) & -0.11 & (-1.09 ; 0.81) & 0.38 & (-0.29 ; 1.00) \\ & & & & & & & & & \\ 7.42 & (2.68 ; 11.87) & 1.43 & (0.84 ; 1.99) & 5.54 & (1.09 ; 9.73) & 0.04 & (-0.56 ; 0.62) & 0.59 & (0.20 ; 0.98)\end{array}$

Total (Age $\geq 25)$

$7.42 \quad(2.68 ; 11.87)$

$1.43-(0.84 ; 1.99)$

$(1.09 ; 9.73)$

$(-0.56 ; 0.62)$

$(0.20 ; 0.98)$

Women

$\begin{array}{rrr}\text { Age -groups } & & \\ 25-64 & 12.37 & (-3.44 ; 24.58) \\ 65-74 & 10.60 & (-3.28 ; 21.66) \\ 75-84 & 13.62 & (5.89 ; 20.57)\end{array}$

$1.09 \quad(-0.76 ; 2.71)$

$1.49 \quad(-0.18 ; 2.97)$

$2.45 \quad(1.42 ; 3.39)$

$2.24 \quad(-5.39 ; 9.06)$

$0.45 \quad(-0.47 ; 1.31)$

$10.88 \quad(3.55 ; 17.42)$

$7.66 \quad(-0.27 ; 14.72)$

$5.29 \quad(-5.87 ; 14.66)$

$1.88 \quad(0.94 ; 2.74)$

$1.02 \quad(0.00 ; 1.98)$

$0.62 \quad(-0.68 ; 1.80)$

$8.05 \quad(3.21 ; 12.48)$

$1.28 \quad(0.69 ; 1.85)$

\subsection{4 \\ 8.37 \\ 10.92}

$-1.14$

$(-6.75 ; 19.35)$

$(-4.18 ; 18.93)$

$(3.70 ; 17.48)$

$(-8.12 ; 5.11)$

$6.54 \quad(-0.52 ; 12.72)$

$6.49 \quad(-0.92 ; 13.06)$

$0.96 \quad(-9.11 ; 9.73)$

$4.79 \quad(0.31 ; 8.92)$

Total (Age $\geq 25)$

P: temperature location-specific percentile 
Supplementary table 3. Attributable number (AN) of deaths caused by non-optimum temperatures and its $95 \%$ confidence interval (95\%CI) by sex, age and educational level groups. Barcelona (Spain), period 1992-2015.

$\begin{array}{ccccc}\text { All temperatures } & \text { Extreme cold } & \text { Moderate cold } & \text { Moderate heat } & \text { Extreme heat } \\ {\left[\text { lower than } 9.2^{\circ} \mathrm{C}\right.} & {\left[9^{\circ} \mathrm{C}(5 \text { th } \mathrm{P})-25^{\circ} \mathrm{C}\right]} & {\left[25^{\circ} \mathrm{C}-30.6^{\circ} \mathrm{C}(95 \text { th } \mathrm{P})\right]} & {\left[\text { higher than } 30.6^{\circ} \mathrm{C}\right.}\end{array}$

(5th P)]

AN $95 \%$ CI AN

$95 \% \mathrm{CI}$

$\mathbf{A N}$

$95 \% \mathrm{CI} \quad \mathrm{AN}$

$95 \% \mathrm{CI}$

AN

$95 \%$

Men Age -groups

$\begin{array}{rccrc}25-64 & -673 & (-4718 ; 2688) & 88 & (-340 ; 478) \\ 65-74 & 3747 & (130 ; 6820) & 790 & (355 ; 1190) \\ 75-84 & 4561 & (-176 ; 8740) & 675 & (80 ; 1222) \\ \geq 85 & 4554 & (646 ; 7919) & 832 & (328 ; 1289)\end{array}$

$\begin{array}{rcr}-948 & (-4561 ; 2154) & 97 \\ 3458 & (108 ; 6359) & -320 \\ 2962 & (-1542 ; 6965) & 374 \\ 3626 & (-99 ; 6824) & -67\end{array}$

$(-347 ; 511)$

$(-803 ; 138)$

$(-182 ; 896)$

$(-558 ; 389)$

83

-51
667

$(-219 ; 351)$

$(-375 ; 244)$

$(300 ; 1007)$

Educational level (Age $\geq 25$ )

Without studies

Primary education

More than primary education

$\begin{array}{llll}1210 & (-3369 ; 5123) & 341 & (-196 ; 835) \\ 4018 & (-608 ; 8078) & 830 & (262 ; 1364)\end{array}$

$\begin{array}{rlr}583 & (-3533 ; 4126) & 47 \\ 2996 & (-1350 ; 6884) & -4 \\ 4952 & (696 ; 8732) & -7\end{array}$

$(-445 ; 506)$

$(-608 ; 502)$

$(-684 ; 508)$

285

$(-38 ; 577)$

$6044 \quad(1331 ; 10095) \quad 1109 \quad(551 ; 1637)$

4952

$(696 ; 8732)$

$-71$

$9130 \quad(1793 ; 16061)$

66

$(-927 ; 1020)$

221

351

$(-106 ; 527)$

$240 \quad(-171 ; 621)$

Total $($ Age $\geq 25)$

$12226 \quad$ (4392; 19551)

$2363 \quad(1377 ; 3294)$

(2)

(

$980 \quad(331 ; 1605)$

\section{Women}

\section{Age -groups}

$65-74$

1903

2121

$(-506 ; 3793)$

$(-602 ; 4297)$

299

168
299

$(-124 ; 417)$

$(-42 ; 603)$

1176

1676

$(-1064 ; 2962)$

$(-926 ; 3796)$
$(1828 ; 9093)$

298

$75-84$
$\geq 85$

$146 \quad(3022 ; 10737)$

1286
379

$(753 ; 1788)$

5728

$(-6935 ; 4394) \quad 834$

$(3 ; 568)$

$(-370 ; 315)$

$(-719 ; 387)$

(144; 1486$)$

327

205

541

1622

(137; 494)

$(-20 ; 405)$

$(171 ; 885)$

Educational level (Age $\geq 25$ )

Without studies

Primary education

7627

4582

$(-265 ; 9042)$

743

3956

$(-455 ; 7948)$

$-484$

$(132 ; 1335)$

$(-1112 ; 118)$

1245

(1188; 2033)

More than primary education

$1899 \quad(-1930 ; 5208) \quad 224 \quad(-250 ; 644)$

345

$(-3261 ; 3570)$

$(166 ; 1035)$

611

$(847 ; 1617)$

$(197 ; 983)$

$(478 ; 1048)$

Total $($ Age $\geq 25)$

$13812 \quad(5610 ; 21294) \quad 2201 \quad(1191 ; 3174)$

$8208 \quad(586 ; 15230)$

984

$(-24 ; 1948)$

$2729 \quad(2101 ; 3336)$

P: temperature location-specific percentile 